$\mathbb{T}$ periodica polytechnica

Mechanical Engineering $56 / 2(2012) 105+110$

doi: 10.3311/pp.me.2012-2.05 web: http://www.pp.bme.hu/me

(c) Periodica Polytechnica 2012

RESEARCH ARTICLE

\section{Recent technique for thermal-fatigue simulation of heat-resistant steels}

Tamás Bíró / József Csizmadia

Received 2012-06-30

\begin{abstract}
Gleeble 3800 thermal-mechanical physical simulator is introduced in this study. Thermal fatigue tests can be carried out in Gleeble simulator in highly controlled conditions. Applying the same tested material, specimen geometry and temperature range, the load of the specimen can alter more than one order of magnitude depending on the control parameters. Some investigations have been done to demonstrate the effect of the boundary conditions (simulation combinations) on the load and strain of the tested specimen.
\end{abstract}

\section{Keywords}

thermal-fatigue $\cdot$ heat-resistant steel $\cdot$ material testing $\cdot$ simulation

Tamás Bíró

Department of Materials Science and Engineering, BME, H-1111 Budapest, Bertalan L. u. 7, Hungary

e-mail: birotom2@gmail.com

\section{József Csizmadia}

Mechanical Engineering \& Materials Science Department,University of Pittsburgh, 3700 O'Hara Street, Pittsburgh,PA 15261, USA

e-mail: joc84@pitt.edu

\section{Introduction}

Damage processes of heat-resistant steels in operative conditions used to be modelled in laboratory tests [1,2]. In most cases the laboratory tests are carried out such a way, that the specimen is subjected to hetating-cooling cycles, while its thermal expansion is constrained. The load of power plant pipelines during the shut down and start up cycle is modelled this way when the thermal expansion is constrained. Several thermal-fatigue tests have been carried out on the Department of Materials Science and Engineering at Budapest University of Technology and Economics, where the microstructure of the damaged specimens has been investigated by destructive and non-destructive methods [1--4]. Actually, during the "classic" thermal-fatigue test, nothing is known about the real load of the specimen and what is more, the temperature distribution is non-uniform. This thermal-fatigue test is applied for modelling the change of microstructure during the damage process. As the test machine design influences the test conditions and the specimen load, only in the same type machine impaired specimens are comparable with each other. In the following a recent thermal-mechanical simulator will be introduced, which is capable for controlling and measuring all required test parameters during the simulations.

\section{Applied equipment}

Modern devices in the measuring techniques provide new opportunities in the thermal-fatigue tests. Gleeble 3800 thermal-mechanical physical simulator of Gleeble Laboratory of Dunaújváros is a potential prospect for implementing thermalfatigue simulation under controlled conditions [9].

Gleeble 3800 thermal-mechanical physical simulator (Fig. 1) is an extraordinary equipment, which is capable of physical simulation of heat and mechanical load induced changes in metals. The direct resistance heating system of the Gleeble 3800 can heat specimens at rates of up to $10,000^{\circ} \mathrm{C} /$ second. High thermal conductivity grips hold the specimen, making the Gleeble 3800 capable of high cooling rates. An optional quench system can achieve cooling rates in excess of $10,000^{\circ} \mathrm{C} /$ second at the specimen surface.

Thermocouples or an optional infrared pyrometer provide sig- 
nals for accurate feedback control of specimen temperatures. Because of the unique high speed heating method, Gleeble systems typically can run thermal tests 3 to 10 times faster than conventional furnace equipped machines [6].

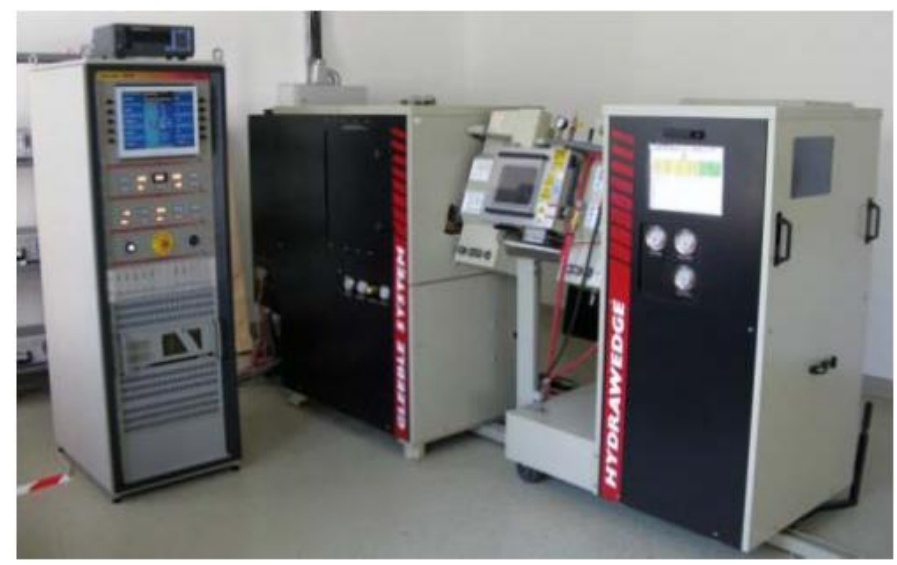

Fig. 1. Gleeble 3800 equipment [5]

The Gleeble 3800 mechanical system is a fully integrated hydraulic servo system capable of exerting as much as 20 tons of static force in compression or 10 tons in tension. Displacement rates as fast as $2000 \mathrm{~mm} / \mathrm{second}$ can be achieved. Load cells and non-contact laser extensometry provide feedback to insure accurate execution and repeatability of the mechanical test program

The right head of the specimen is fixed by a cooled grip. The left head of the specimen is connected to the hydraulic cylinder which generates the controlled load. Work chamber is seen in Fig. 2. The heart of the Gleeble 3800 is the Series 3 Digital Control System. It provides all the signals necessary to control thermal and mechanical test variables simultaneously through the digital closed-loop thermal and mechanical servo systems. The Gleeble 3800 can be operated totally by computer, totally by manual control. The embedded processor executes test and simulation programs and collects data [6].

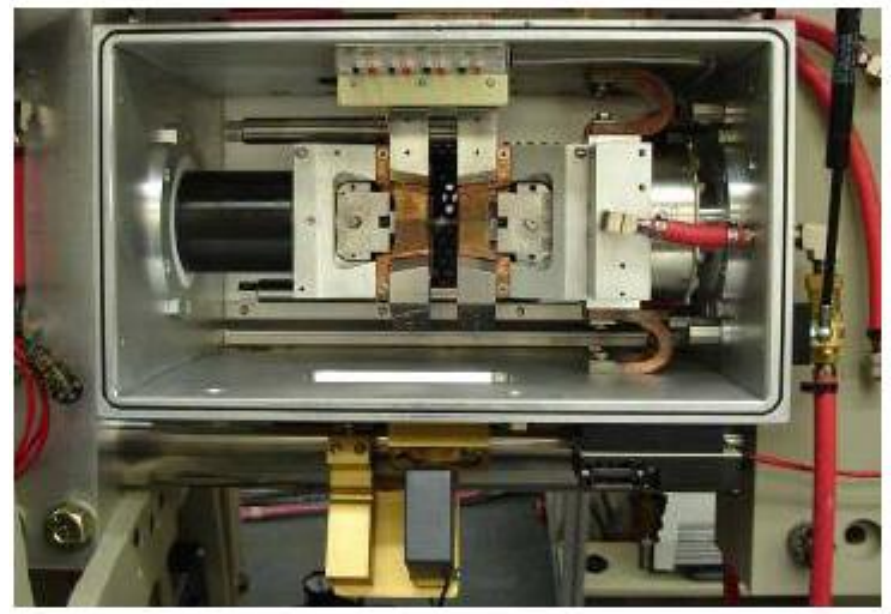

Fig. 2. Work chamber of Gleeble 3800 [7]
Tab. 1. Parameter combinations

\begin{tabular}{llll}
\hline $\begin{array}{l}\text { Name of the } \\
\text { parameter } \\
\text { combination }\end{array}$ & $\begin{array}{l}\text { Control } \\
\text { sign }\end{array}$ & $\begin{array}{l}\text { Measuring } \\
\text { device }\end{array}$ & $\begin{array}{l}\text { Hydraulic } \\
\text { pressure }\end{array}$ \\
\hline SH0 & Stroke & HZT & 100 bar \\
SH1 & Stroke & HZT & 300 bar \\
SL0 & Stroke & L-Gauge & 100 bar \\
SL1 & Stroke & L-Gauge & 300 bar \\
HH0 & HZT & HZT & 100 bar \\
HH1 & HZT & HZT & 300 bar \\
LL0 & L-Gauge & L-Gauge & 100 bar \\
LL1 & L-Gauge & L-Gauge & 300 bar \\
\hline
\end{tabular}

\section{Thermo-mechanical pre-simulation}

When we want to make similar to the previous "traditional" tests [3] 4], there are many options in Gleeble machine to set the test parameters and the boundary conditions of the test control. This is very important, because beside the temperature cycles it defines the mechanical stress of the specimen during the simulation.

The "stiffness" of the specimen clamping depends on the control sign of the simulation program, measuring art of the displacement and the hydraulic pressure. The aim of the presimulation is to determinate the simulation parameters which similar to the conditions of the "traditional" thermal-fatigue machine applied before [3, 4]. The temperature range was $100^{\circ} \mathrm{C}$ $550^{\circ} \mathrm{C}$, the heating rate was $25^{\circ} \mathrm{C} / \mathrm{sec}$ and the cooling was executed through the heat removal of the cooled grips. Tested material was an unalloyed carbon-steel, with $10 \mathrm{~mm}$ nominal diameter.

List of keys are applied in the following simulation:

- Stroke displacement of the hydraulic cylinder [mm]

- L-gauge displacement of the internal distance of the grips [mm]

- HZT071 displacement of the initially $10 \mathrm{~mm}$ gauge on the middle section of the specimen [mm]

- Force axial load of the specimen (positive at tension) [N]

- Temperature surface temperature of the middle cross-section of the specimen $\left[{ }^{\circ} \mathbf{C}\right]$

The control sign means during the Gleeble simulations that, the control of hydraulic system constraining the sample is driven by the given displacement sign. Measuring device means which device is set to measure the axial displacement of the measured cross section of the specimen. Hydraulic pressure is 100 bar in most applications. It can be increased up to 300 bar, which results "stiffer" hold, but it overloads the hydraulic system of the simulation equipment.

Fig. 1 shows the load and the displacements of the specimen tested in $\mathrm{HHO}$ combination. HH combination means the most intensive displacement compensation, because the hydraulic system compensate the thermal expansion so intensive that the 
$10 \mathrm{~mm}$ spaced gauge at the middle section of the specimen do not change during the simulation. Since this the HH combination is the "stiffest" clamping. The maximal loads of the specimen at $\mathrm{HH} 0$ combination is $+30 \mathrm{kN}$ and $-40 \mathrm{kN}$. It should be higher, but the hydraulic system was not able to compensate the thermal expansions. This statement is supported by the fact that force-plateaus seen at temperature peaks. (Fig. 3) The displacement parameters are apparently not synchronous with the temperature while Gleeble simulator keeps HZT071 at a minimal level. But this chaotic diagram is only a control technique resonance, which can be eliminated a small parameter modification.

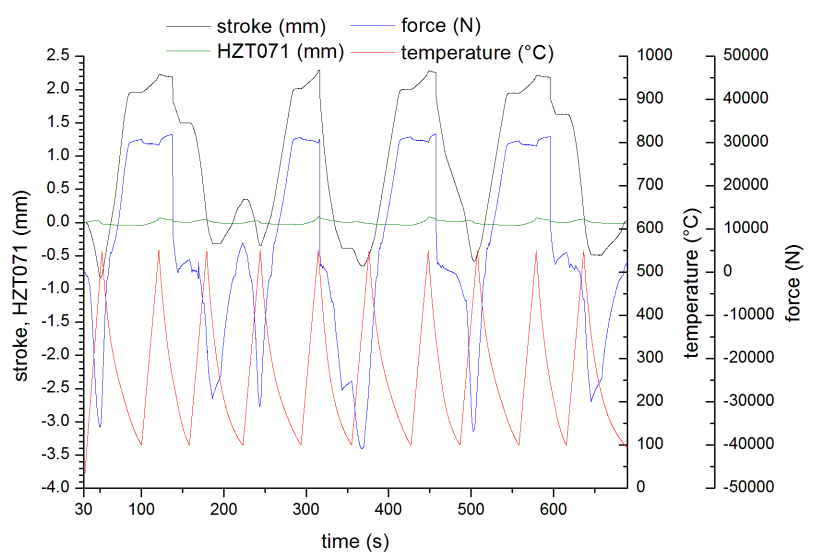

Fig. 3. Results of $\mathrm{HHO}$ combination versus time.

The modification of $\mathrm{HH} 0$ combination was to increase the hydraulic pressure to 300 bar, in order to eliminate the saturation (Fig. 3). As it can be seen in Fig. 4 the increased 300 bar hydraulic pressure was enough to compensate the force derived from the thermal expansion. As result of this parameter modification temperature activated periodic process control could evolved (Fig. 4).

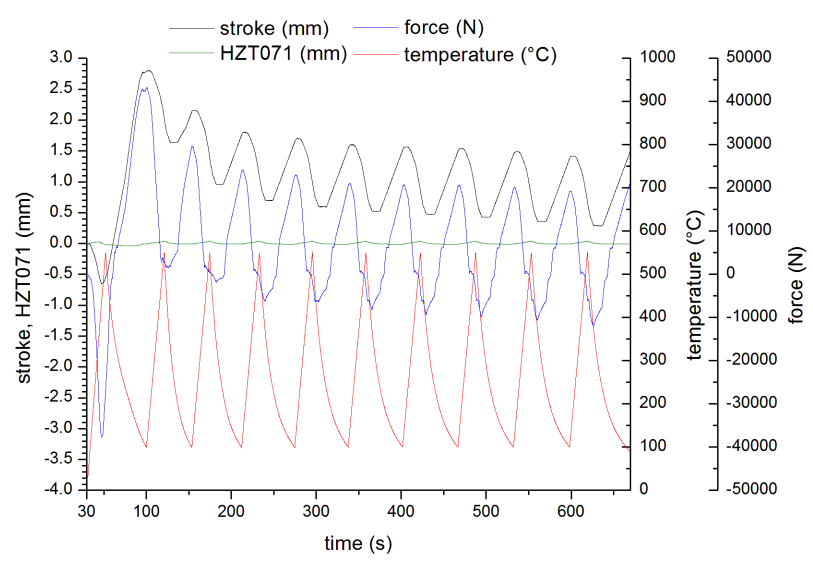

Fig. 4. Results of HH1 combination versus time.

In Fig. 4 the force and deformation data are in synchronized periods with the thermal cycling. All force and deformation data follow a little bit delayed to the thermal-cycling which phenomena caused by the thermal sluggish, that is why $3 \mathrm{sec}$ thermal hold is required at $550^{\circ} \mathrm{C}$ temperature. It can be noticed that the force became almost symmetric after 10 heating-cooling cycles, but at first it was totally asymmetric. Fig. 5 shows the same measurement data as Fig. 4 (HH1 combination), but the displacement data are enlarged to be analyzed. It is very important to notice, that HZT071 values changing in approx., 0,04 mm range. Actually it means that the control system can hold constant in $0,04 \mathrm{~mm}$ range $(0,04 \mathrm{~mm}$ inaccuracy) the initially $10 \mathrm{~mm}$ gauge length of the specimen.

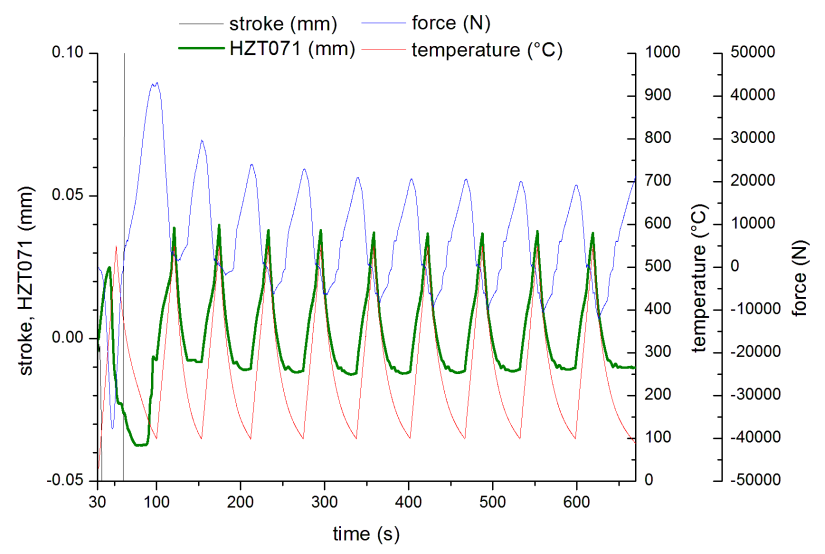

Fig. 5. Results of HH1 combination versus time with enlarged displacement data.

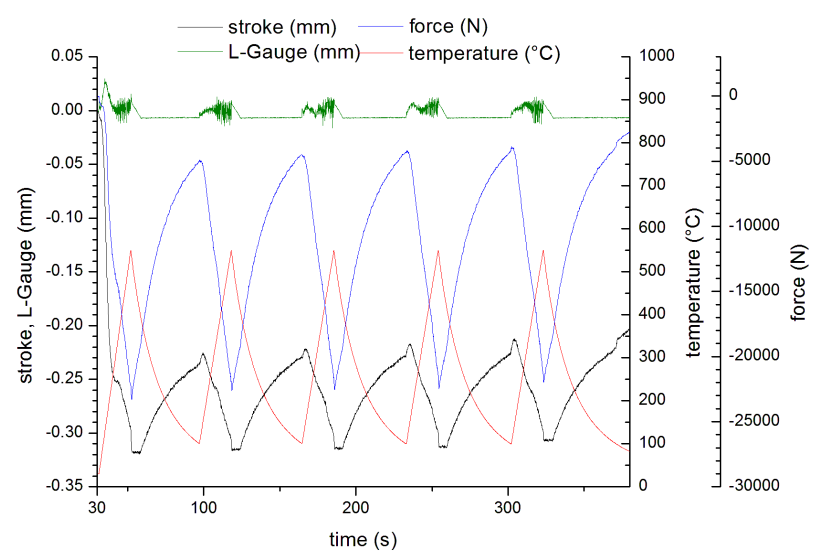

Fig. 6. Results of LL1 combination versus time.

When the L-gauge was the control sign (LL0 and LL1 combinations) - that the hydraulic cylinder holds the distance of the grips constant - the following results were measured during the thermal-fatigue simulation (Fig. 6). As the control is driven the $25 \mathrm{~mm}$ specimen length, the axial thermal gradient of the specimen is not negligible. The nominal test temperature is valid only at the middle cross section of the specimen. Toward the grips, the specimen temperature is even lower, that means the thermal expansion of the specimen is lower, than it would be at 
uniform temperature distribution. This phenomenon is known at "traditional" thermal fatigue machines also [1]. Considering the above detailed facts, it was clear that the force $(\sim 18 \mathrm{kN})$ lower than at HH combinations. So apparently the "stiffness" of the specimen clamping is lower also. Hydraulic cylinder displacement (Stroke) was $\sim 0,3 \mathrm{~mm}$, which is approx. one magnitude order lower than at $\mathrm{HH}$ combinations. As the simulation results of combinations LL0 and LL1 did not show any important difference, only the LL1 is shown in this paper.

In the following the combinations will be demonstrated where the control sign the stroke was. Actually it means that the hydraulic cylinder was fixed during the thermal-fatigue simulations. Instead of presenting the diagrams, only the conclusions will be summarized. Results of combinations SH0 and SH1 did not show any remarkable difference. The maximal load force was $\sim 5 \mathrm{kN}$, and it was steadily negative (compressive force) during the whole fatigue test.

At SL0 and SL1 combinations showed practically no difference. The maximal load force was $\sim 3,5 \div 4 \mathrm{kN}$, and it was steadily negative also. If the force does not change signum, (steadily negative) it means unequivocally that there was no plastic deformation in the specimen.

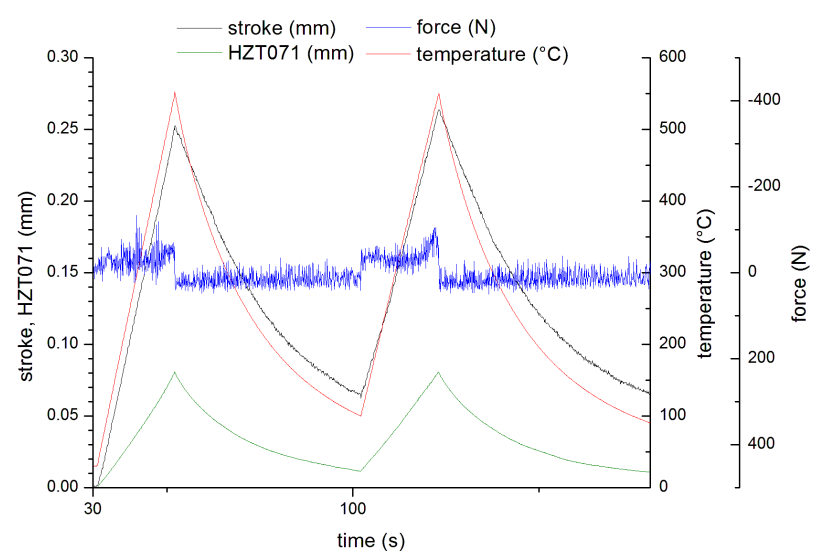

Fig. 7. Free deformations versus time.

Fig. 7 shows the free thermal expansion of the specimen, so there is not fix constraint. The force must be theoretically zero, but the movement of the mechanical element requires some force. This diagram demonstrates the measure of stroke and Lgauge while the thermal expansion was not constrained.

Considering the above detailed measuring results and conclusions, thermal-fatigue simulation of $15 \mathrm{Mo} 3$ specimen follows.

\section{Thermal fatigue simulation of $15 \mathrm{Mo} 3$ heat-resistant steel}

In previous research some thermal-fatigue tests were carried out [3], [4]. Aim of this work is to make similar tests on Gleeble 3800 simulator and compare the results with each other. The number of test heating-cooling cycles was 300 .
Using the pre-simulation parameter combination titles, this simulation has been carried out in LL1 combination. So the sign of L-gauge sensor was the control sign and measuring device too, and the grip distance was controlled as constant. Hydraulic pressure was 300 bar.

This combination had been selected because this control seemed quite similar to traditional thermal-fatigue machine which was applied before [3, 4].

Initial temperature was $30^{\circ} \mathrm{C}$, while the specimen was unloaded. Simultaneously switching on the heating cycle the "stiff hold" was activated and the thermal fatigue simulation started. Temperature range: $100^{\circ} \mathrm{C}-550^{\circ} \mathrm{C}-100^{\circ} \mathrm{C}$. Heating rate was $25^{\circ} \mathrm{C} / \mathrm{sec}$, the holding time at $550^{\circ} \mathrm{C}$ was $3 \mathrm{sec}$, and the cooling was taken by the thermal conductivity grips. During the simulation all measured parameters (force, temperature, L-gauge, stroke) were saved every $0,5 \mathrm{sec}$ and they are demonstrated in the following figures. As the total thermal-fatigue time (300 cycles) would be very crowded in one diagram, only the cycles $0 \div 10$ were presented. This shorter period represents the whole tested range quite well, and it is suitable for studying the behaviour of $15 \mathrm{Mo} 3$ material (Fig. 8). The measuring data show that the maximal force of the specimen was $\sim 6.7 \mathrm{kN}$. The maximal force was developed at maximal temperature in each cycle. The calculated axial compression stress was $130 \mathrm{MPa}$, which was equal to the yield-stress of the specimen at the actual temperature. In the first cycle the axial compression stress reached the yield stress, and a small plastic deformation occurred in the specimen. During the holding time on $550^{\circ} \mathrm{C}$ the force dropped about $200 \mathrm{~N}$ which confirmed the plastic deformation also (Fig. 8). This fact is proved by the calculated stress compared to the yield stress of $15 \mathrm{Mo} 3$ material (Fig. 11). The yield stress data are from the material specification [8].

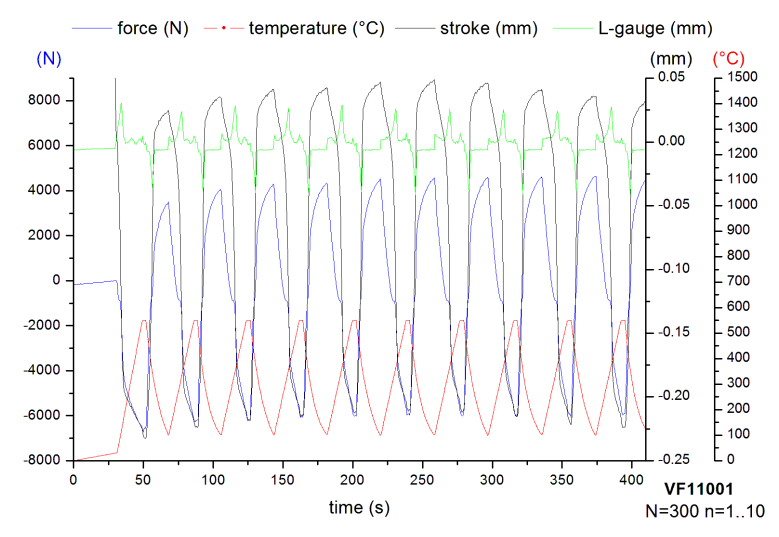

Fig. 8. Thermal-fatigue simulation results of $15 \mathrm{Mo} 3$ material versus time $(0-10$ cycles $)$.

After the first heating-cooling cycle, the loading force signum changed from negative into positive and it is changing in each cycle. But from the second cycle was no plastic deformation in the sample, it suffered only elastic deformation. There was 
no more force drop in the holding time in the following cycles (Fig. 10).

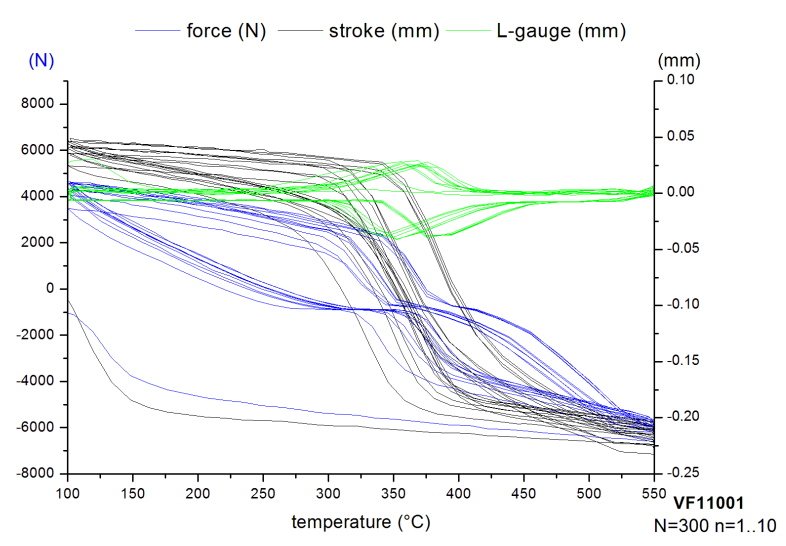

Fig. 9. Thermal-fatigue simulation results of $15 \mathrm{Mo} 3$ material versus temperature.

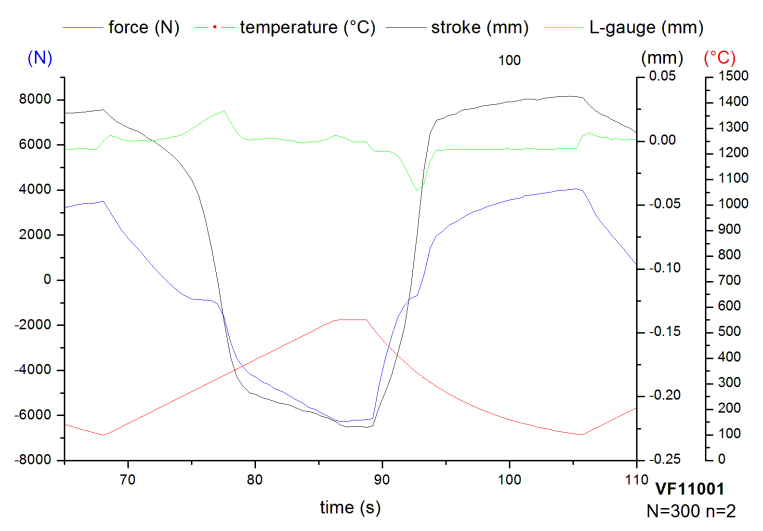

Fig. 10. Second cycle of the $15 \mathrm{Mo} 3$ thermal-fatigue simulation.

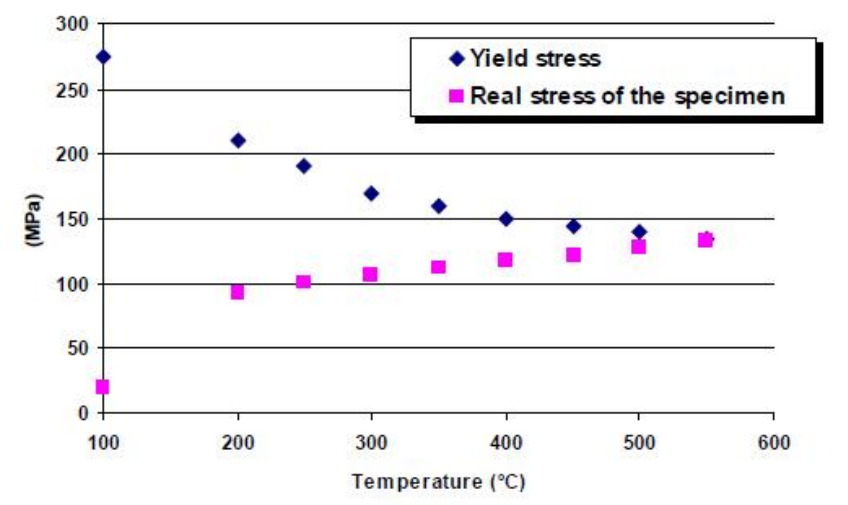

Fig. 11. Compression stress in the specimen during the stress versus temperature.

As it seen in the measured results, after the first thermal cycle, there was no more plastic deformation in the sample in the applied thermal range $\left(100 \div 550^{\circ} \mathrm{C}\right)$. So there was no thermal fa- tigue anymore. That is why it is no use doing more simulations with different cycle time.

\section{Summary}

Aim of this work was to introduce Gleeble 3800 simulator and investigate its suitability for doing thermal-fatigue simulations. It is clear, that there are many opportunity and many variations of test parameters. In pre-simulation it was compared how the stress and strain of the specimen changing at different combinations (control sign, measuring device, hydraulic pressure). Evaluating the results, the following can be stated:

Gleeble 3800 simulator has a really excellent controlled digital closed-loop thermal and mechanical servo systems. During the simulations the control signs were defined as different displacement data, which was hold in a range $\sim 0,02 \div 0,04 \mathrm{~mm}$ even at $40 \mathrm{kN}$ load force. These small deviations mean very good accuracy in absolute value. But it is important to notice, that this small "inaccuracy" amounts a remarkable portion of the thermal expansion of the gauge length. Fig. 7 shows the free deformation values of the specimen, when the thermal expansion is not constrained. For example max value of HZT071 is about $0,08 \mathrm{~mm}$, but more than $40 \%$ of this thermal expansion is "absorbed" by the control. (see Fig. 5. HH1 combination) So the "theoretically stiff" locking of the specimen is not possible despite of the high-accurate control. Increasing the gauge length of the specimen would improve this phenomenon, but the thermal in-homogeneity would strongly influence the measuring results.

Based on the material specification of $15 \mathrm{Mo} 3$ [8], heating the ideally stiff fixed bar from room temperature, it reaches the yield stress at $\sim 140^{\circ} \mathrm{C}$. Above this temperature, the deformation is fully plastic. Despite of this calculation, during the simulation with LL1 combination this steel reaches the yield stress at $550^{\circ} \mathrm{C}$.

Increasing the hydraulic pressure up to 300 bar is reasonable in case of $\mathrm{HH}$ combination. Applying any other combinations, it is no use overloaded the hydraulic system, because it is causeless from the aspect of simulation results. Apart from the HH combination, 100bar hydraulic pressure is proper for this thermalfatigue simulation.

It is one of the most important key in theses simulations is to pick out the proper combination, because it determines the "stiffness" of the specimen clamping. Applying the same specimen geometry and thermal cycle range, the loading force can alter more than one order of magnitude $(3 \mathrm{kN} \div 40 \mathrm{kN})$ depending on the combination. And of course depending on the combination of the simulation the specimen can suffer elastic or plastic deformation. From the aspect of thermal-fatigue, the pure elastic deformation is irrelevant, because it does not cause the damage of the specimen.

At combination $\mathrm{HH} 1$, the specimen suffers a amplitude stimulated low-cycle fatigue, which zero point approaches the value 0 N. (see Fig. 4)

Doing thermal-fatigue simulation on material $15 \mathrm{Mo} 3$ at com- 
bination LL, the specimen suffers only elastic deformation (except for the first heating cycle).

When the hydraulic cylinder "stroke" is set as control sign, the stress of the specimen is far under the yield-stress. This is caused by the physical fact, that the thermal distribution in the specimen is inhomogeneous, and the cooler regions can absorb the higher thermal expansion of the warmer regions.

\section{References}

1 Kwak D., Micro-Magnetic Examination of Thermal Fatigued Heat-Resistant Steels, 2004. PhD dissertation.

2 Ginsztler J, Hốciklusok hatása hazai erômúvek szerkezeti anyagainak tulajdonságaira, 1973. Műszaki doktori értekezés.

3 Biro T, Szabó PJ, Effect of Thermo-mechanical Fatigue on the Microstructure of Steels, Material Science Forum 473-474 (2005), 183-188. (c)2005 Trans Tech Publications.

4 Bíró T, Mészáros I, Ginsztler J, Magnetic Investigation of the Microstructural Effects of Creep and Fatigue Process, Gépészet 2004 Proceedings of Fourth Conference on Mechanical Engineering, Vol. 1, Budapest University of Technology and Economics, 2004, pp. 23-27.

5 Csizmadia J, Farkas P, Optimizing of Rolling Schedule in Case Hot Rolling of AA8006, Aiud, BKF 2010, 202-207.

6 WWW.gleeble.com

7 Gonda V, Csepeli Zs, Kardos I, Verö B, Csizmadia J, Hot ductility variations of ST52-3 continuously cast steel within the cast strand, Materials Science Forum 659 (2010), 13-18, DOI 10.4028/www.scientific.net/MSF.659.13.

8 www.thyssenkrupp-stahlkontor.de/tl_files/ThyssenKrupp/pdf/ 16Mo3.pdf

9 Jandová D, KasI J, Výrostková A, Csizmadia J, Jenei I, Comparison of results of long-time creep test and ACT of dissimilar weld joint of steel P22 and P91, Proceedings of the IIW International Conference (Kulkarni DV, ed.), Narosa Publishing House, New Delhi, 2011, pp. 910-916. 